\title{
The value and contribution of foster families in the deinstitutionalization of the mentally ill
}

\author{
Olga Velentza \\ RN, Aiginiteio Hospital, Athens, Greece
}

\section{Email address:}

olyvelen@gmail.com

\section{To cite this article:}

Olga Velentza. The Value and Contribution of Foster Families in the Deinstitutionalization of the Mentally Ill. American Journal of Nursing Science. Special Issue: Mental Health Care: Aspects, Challenges and Perspectives. Vol. 4, No. 2-1, 2015, pp. 31-36.

doi: 10.11648/j.ajns.s.2015040201.17

\begin{abstract}
Introduction: The family is the first place where the values, principles and standards are instilled and absorbed. It is the main natural support system for the member who suffers from a serious mental disorder and it can play an important role in the progress and development of mental illness. Purpose: The purpose of this paper is to study the institution of the foster families in Greece, since it is considered innovative for the institutionalization of the mentally ill within the psychiatric reform. Material and method: Literature search from electronic databases Scopus, Ebsco, Pubmed, Wiley, was performed and 31 articles by Greek and foreign literature were isolated and studied. Information from EKEPSYE was sought as well as the testimony of responsible programs in Greece. A study was made on Programs of foster families, as well as analysis and an analysis of experience thus giving useful practices of Greece as well as abroad. Results: The placement and the staying of chronic patients under the care of foster families, provided that they continued their treatment, can help prevent relapses, as well as hospitalization. It can also improve the quality of life of the patient, reduce the cost of services. Thus enhancing the functioning of the patient as to become able in future to lead a more independent lifestyle. Conclusions: The institution of psychiatric reform and the principles are the basis for the development and implementation of foster families, with a view to the de-institutionalization of the mentally ill and a healthy transition into the community.
\end{abstract}

Keywords: Foster Families, Foster Family, Psychiatric Reform, Intermediate Structures

\section{Introduction}

The institution of the foster families is concerned with families who undertake the responsibility to put up and care for mentally ill patients who are not able of caring for themselves. According to research and design of suitable programs in Greece as well as other countries, the staying of the mentally ill in foster families is not only beneficial to the patient for his mental state and development, but it is also beneficial for the social services as it is more economical to place patients under the care of foster families rather than place the mentally ill patient in psychiatric hospitals, boarding houses or hostels. [1-3] The institution of the foster family programs are concerned with alternative housing structures which, in accordance with the Law 2716/1999, were implemented in order to place adults with psychiatric disorders, along with psychiatric care of course, with families which are selected according to predefined criteria and are under the control of the interdisciplinary team.

They often operate under the name of Foster families, and in fact in both, the Foster family and foster family, are placed adults or not who for various reasons cannot survive or take care of themselves alone.

In Greece the term foster family is broader and covers both children, adolescents and adults. The term foster families is regarded as restrictive and is concerned with the placement of mentally ill people and they are set up by University Psychiatric Hospitals, University Institutes of Mental Health and Mental Health Units. It is worth noting that both programs concerning people with mental disorders and are currently implemented in our country have the title "Programs of foster family". [4-6]

\section{Institutional Framework of Operation Law 2716/1999}


The term of "Foster family" was first introduced in the late 1990s and in the overall need for the implementation of the psychiatric reform and the principles of the country. The Law 2716 of 1999 introduced a series of reforms on the "Development and modernization of mental health services" as are defined in Article 9 Law 2716/1999 concern "units or programs that provide psychosocial rehabilitation services for adults, children or adolescents and boarding schools, hostels, protected apartments and foster families. [4-5-7]

\section{Reasons for Activating the Institution}

The institution of the Foster families is one of the established housing structures within the psychiatric reform. The reasons for choosing host families for a long term institutionalized patients are many, such as offering physical, emotional, social, and new experiences to the patient, which characterize the community care and at the same time reduce and eliminate asylum-like habits, depersonalization and désocialisation that the patient has received and has been deprived during his institutionalization. The placement of the institutionalized person in a foster family serves the objectives of the reduction of large institutions, deinstitutionalization, the upgrading and reform of the existing services and promoting community care. The psychiatric reform aims to eliminate the institutional characteristics of the system of psychiatric services in the country and to develop the Community model of care for the mentally ill.

This model is based on the principles:

- Addressing the social exclusion

- The outpatient care

- Social psychiatry

- The sectorization

- Psychosocial rehabilitation

- Social inclusion

The need for change in the way that the mental health services are used was not only expressed through the legal framework and the principles of psychiatric reform.

At international level, the report for the World Health (WHO 2001) set the necessary continuous shift from psychiatric hospitals and asylums to the provision of community care, arguing that this type of care has better results regarding quality of life, respect for human rights and economic performance in relation to the care provided in asylums. The report acknowledged the community care as the provision of an integrated group of services provided by professionals from different fields and establishes appropriate bonds with other sectors, such as housing and employment. (Evaluation report on mental health). In Greece, until the 1980s, the system of care for people with mental, intellectual or physical disabilities, followed by the type of closed residential care. This constituted institutions, mental hospitals and asylums, which functioned as places of incarceration and not of care, were in very poor conditions and they were understaffed and run by unskilled workers. The result was to create in the country a wide and multiannual program of deinstitutionalization and creating new Community model care, which was supported and continues to be supported by the European Union.

The mentally ill in community units compared to the mental hospital have:

- Better living conditions

- Fewer restrictions

- Emphasis on autonomy and taking initiatives

- Emphasis on the use of facilities and resources in the community

- Experienced improvement in their social function

- Reduction in negative psychiatric symptoms

- Expansion of the social network support [8-12]

The psychiatric reform and the deinstitutionalization of the mentally ill is not only limited to the conversion of provided mental health services to the community psychiatry and community structures to create housing.

Sakelaropoulos (2003) referring to the concept of deinstitutionalization notes that: "there is a parallel process that moves in six areas:

- The change of attitude of the population and awareness of new forms of psychiatric care.

- The establishment and organization of primary and secondary care (general hospital) community.

- The close relation and cooperation of these services in order to reduce admissions to the mental hospitals.

- The radical improvement of therapies and lifestyle of patients in psychiatric hospitals.

- Redefining the social role of patients by joining prevocational training programs and social limited partnerships.

- Finally, the final release of psychiatric patients and their placement into intermediate structures. [3-13-16]

Table 1. Implementation Process Programs Of Foster Family

\begin{tabular}{lll}
\hline Preconditioning & Opening stage & Implementation Phase \\
\hline Recommendation Therapeutics & File Transfer & Definition of Patients \\
assistive & Recommended foster families \\
Interdisciplinary Team & Program in D / Address & \\
and & Mental Health & Patients and Hosting \\
definition Scientific & Ministry of Health and Social solidarity & Family Inclusion in Patient \\
responsible & foster Family \\
& Project Description (Therapeutic Team) & Family and \\
\hline
\end{tabular}




\begin{tabular}{|c|c|c|}
\hline Preconditioning & Opening stage & Implementation Phase \\
\hline suitable candidates for & & patient support \\
\hline admission to the patients program & $\begin{array}{l}\text { Duration and } \\
\text { budget }\end{array}$ & Monitoring progress and \\
\hline $\begin{array}{l}\text { Research and communication } \\
\text { campaign to attract }\end{array}$ & program & progress program \\
\hline foster family & $\begin{array}{l}\text { Programming } \\
\text { monitoring }\end{array}$ & Evaluation of foster \\
\hline $\begin{array}{l}\text { Setting Techniques } \\
\text { characteristics }\end{array}$ & Program etc. & family \\
\hline program: & $\begin{array}{l}\text { Proposal evaluation } \\
\text { the D / Department of Mental Health }\end{array}$ & $\begin{array}{l}\text { Actions to promote } \\
\text { patient in employment }\end{array}$ \\
\hline - Origin of resources & & \\
\hline $\begin{array}{l}\text { - Ensure } \\
\text { funding }\end{array}$ & $\begin{array}{l}\text { Approval or not of the } \\
\text { program }\end{array}$ & \\
\hline $\begin{array}{l}\text { - Level of allowance } \\
\text { - Duration of the program }\end{array}$ & $\begin{array}{l}\text { Securing funding } \\
\text { through public or private, } \\
\text { State or Community } \\
\text { resources. }\end{array}$ & $\begin{array}{l}\text { Procedure and preparation of the patient for independing } \\
\text { living }\end{array}$ \\
\hline
\end{tabular}

$[4-5-7-17]$

Conditions For Placement Of Patient In Foster Family

- Written request of the referring agency.

- Examination of the patient's records of the Interdisciplinary Group imports.

- Transfer Patient in "House Watch" in the city as interim housing structure.

- Definition of the foster families from the foster family list on hold.

- Patient and foster family meeting.

- Patient moving to the foster family's home. [18-20]

\section{Profile of the Foster Family}

Through the study of foster family programs here in Greece as well as other countries we come to the conclusion that despite the difficulties of finding families willing to take on psychiatric patients usually the foster families are distinguished by some common characteristics. The average foster family consists of people who have family ties with the patient and they are mostly the siblings of the patient. We also notice there are also foster families of uncles and aunts of the patient but this occurs less frequently. This happens due to the fact that the law does not allow A degree relatives to accommodate patients and thus create a foster family. At this point we notice a threat against the programs as the change of legal framework and the participation of A degree relatives would mostly solve the problem of finding foster families. Apart from their close relatives, people who have friendly relations with patients or working in the field of mental health is likely to be a foster family. It is worth noting that the legislature allows the foster family to be even one member. Finally, it has been observed that the age of the members of the foster family is between 49 to 60 years old. Apparently they have life experience, which they can rely on in order to take care of the patient. Since we are talking about patients with serious illness it has been observed the foster family are people who have either retired or their job allows them to have enough time to devote to their guests. In future communication activities should target to such categories in order to find foster families. [10-14-15-21-24]

\section{Implementation of the Program in Greece for Adults with Mental Disorders}

E.KE.PS.Y.E

The foster family program, which is under the supervision of the center, is the largest program currently in the country and besides Attica it is also run in Crete. The foster family program Leros-Athens E.KE.PS.Y.E was developed in three phases and has been implemented since the end of 1989. In the first phase 10 patients were placed in foster families. A year later a second group joined the program consisting of 10 patients. The vast majority of these patients came from large psychiatric hospitals in Attica. In 1991, under the deinstitutionalization of the state hospital in Leros, another 8 patients were placed in foster care after their process preparation by the function group "intervention".

The program aims to help psychiatric patients, who for whatever reason are deprived of their natural family, by placing them in foster families and therefore live in healthier and more therapeutic environment.

Frequency of discontinuance of the program by reason of interruption

Reason of discontinuance number of patients

Patient Death: 18

Inappropriate foster family: 8

Patient Refusal: 1

Foster family Refusal: 1

Insufficient data: 6

Total 34

It is worth noting that in the cases stated the reason of discontinuance of the foster family is either the confirmed 
inability of the family to care for the patient, or relapse of the patient and the need to be admitted to a psychiatric institution or the inadequate care of the patient by the foster family which has been certified by the department center. Patients who are placed in foster families are either recommended by the Centre or the institution in which the last resided. They can also be recommended by relatives, other social services, such as the Houses of psychiatric hospitals, community housing and many more. Most patients who are placed in foster care suffer from severe psychiatric diseases and they usually face other health problems.

Specifically patients who are now in foster care

- $70 \%$ suffer from schizophrenia and other psychoses

- $30 \%$ suffer from Down syndrome and mental retardation.

Because these patients have serious health problems a thorough examination of their condition is done. Before they are placed in foster care in order to check the functioning of patients and their ability to live in harmony with the other family members. An important factor in achieving a harmonious living is the age of the patient. During this time, patients between the ages of 27-63 are in the program with an average age of 47 . It is also of great interest that the foster families age, as proven, are older people who in some cases are retired with no other professional obligations but to care for the patients. The average age of the foster family is 53 . Similarly important are the characteristics and motivations of foster families. In most cases the foster families have family ties with their patients or are neighbors and people in the wider circle of the patients. However there are people who work in mental health facilities and are foster families. This fact demonstrates the awareness of these people towards the mentally ill. According to data from E.K.PS.Y.E. it is observed that the vast majority of cases of foster families have been in the program since the program in the center began in 1989. 12 of the 30 patients live in their own apartments within walking distance of the homes of the foster families, who check on them daily as well as care for them. These patients display increased autonomy, are functional and sociable. An important issue for the success of the program of foster families E.KE.PS.Y.E. is the allowance to foster families which greatly supports the continuation of the program and ensuring that the foster family provides a decent standard of living for their patients. The allowance amounts to 540 Euros per month and the net which the foster family receives is 412.56 Euros. This amount is admittedly very low in comparison to the needs of the patients for drugs and living essentials as well as the services that the foster family provides, who often supplement the allowance with their own income in order to cover the needs of the patients. Particularly in cases where the patients live in separate units than that of the foster family, the allowance cover the rent, thus the patients depend on other welfare benefits they receive as well as the contribution of the foster family. [4-525-26]

\section{The Foster Family Unit of Psychiatric Clinic University of Athens}

In 1998, the foster family unit (FFU) of the psychiatric clinic of the University of Athens was inaugurated. The program was designed to gradually place 10 patients in the foster care and to evaluate the results after a two year stay in the foster family. The efficacy criteria were defined as

- Clinical and functional status of the patient.

- Use of services.

- The quality of life of the patient.

- The cost of the foster and his family and

- The relative cost of foster care.

During the 12 year review of the operation of F.F.U.it was observed that 12 psychiatric patients who had been diagnosed as mentally ill, from 9 to 32 years, before the program began, were placed in as many as foster families. Of these 12 fosters , 58\% continue up to date while $42 \%$ have expired. It should be noted that the seven foster families are still continuing today are due to expire the end of the year and will be placed in their own self-catering units. According to data for those which have expired, it appears that from the five foster families, 3 were very successful, as patients live longer independently in their own apartments, or with people they are familiar with and for them the goal for deinstitutionalization has been achieved. However, both of the two patients who returned to asylum structures can partly be described as a success of the program. This is because although these patients were suffering from very serious mental disorders, the entire period of their residence, which ranged from 22 to 115 months, showed no relapse, no fits (outburst) and there was no need to be hospitalized in psychiatric clinics, contrary to the frequency of their relapses before the program of the foster families.

Another feature of the patients who follow the program of foster families is the kind of illness they suffer from. 12 patients of the program, $75 \%$ were suffering from a schizophrenia and the other $25 \%$ were suffering from mental disorders and mental retardation. Regarding some of the characteristics of patients are their age ranges from 33 to 53 years old, both men and women. Respectively foster families' age ranged from 35 to 71 years old, and in some cases there were family ties, grade B and above, without excluding non related foster families. An important factor for the success of the foster family program is the monthly allowance which covers the basic needs of the patient and it is a great help to the foster family, which amounted to 412,45 EURO. [5-7-2728]

\section{Results of the Implementation of the Institution}

\subsection{Positive Aspects of the Implementation of Programs}

Undoubtedly the residence of mentally ill patients in 
housings and not asylums, such as Hotels, supervised apartments and foster families, contributes to the improvement of the clinical condition of patients and their re-establishment into society and it was based on that the application and the psychiatric reform stated in our country. The improvement of the mental state of the patients is proven by the fact that many of the patients who had been placed in foster families managed to live alone in self-catering apartments. Even patients who are still reside with families have shown an improvement of their clinical condition avoiding outbursts (fits), and reduction to in the frequency of their admittance to psychiatric clinics and develop again their social skills. Furthermore living with foster families, many patients were able to come to be in touch with their relatives who had been alienated due to their mental illness. These family members can be an important supportive network during their rehabilitation process to a normal environment.

\subsection{Weaknesses and Problems of the Implementation of the Program}

The major problem encountered for the implementation of the program in Greece, as shown by the data, is mainly the heterogeneity in the way of development programs, because of the members of the support groups, the amount of compensation and the nature of any additional benefits to the families. Despite these problems and shortcomings which are encountered in the development of the foster family program, such as the lack of adequate service and fundings, it is observed that a big part of the mental health professionals has responded with serious intentions and proposals for the further development of such programs which they have to be strengthened and supported in the future. [9,10,17,29,30]

\section{Discussion}

Through discussions with people working in the field of mental health programs as well as the foster families, interesting proposals for the improvement of the programs and the success of their application emerged. These proposals are:

- Promotion and establishment of the institution of professional foster family, where the applicants or the foster families will have health care insurance coverage and receive social security for the period of their membership in the program.

- Promote foster care programs in the region, which will be coordinated either by municipalities or regions, resulting in the development on a larger scale and meet the needs of a greater number of mentally ill patients.

- Promote education of the foster families both before and during the program. It was also proposed that there should be a close cooperation of the caring team, in order jointly to establish a plan to improve the clinical condition of the patient with a schedule and an evaluation of the foster family's work.
- Increase the allowance of undertaker in order to reach the level of institutionalized closed medical expenses and significantly help the work of the undertakers (foster family).

- Provide an integrated framework of incentives for foster families in order to increase interest in the foster family program. [2-10-24-31]

\section{Incentives for Candidates for Foster Families}

- Adequate and non-taxable allowance foster family.

- Tax relief for family members.

- Health Care and Social Security through the Commercial Sponsorship.

- Rent subsidy for the home of the foster family.

- Recognition of years of participation in the program as work experience.

- Financial facilities for obtaining loans on more favorable terms.

- Education of family members in mental health issues, in the form of seminars.

The placement and retention chronic patients under foster families provided continuing therapeutic care can help prevent relapses, hospitalizations, also improve the quality of life, cost of services and the functioning of the patients to become able in the future to move to more independent lifestyles. [1-4-8-10-13]

\section{Conclusions}

The staying of mentally ill patients with foster families contributes both to their mental health and welfare of as well as to the economy, because it is significantly more economical to live with foster families rather than live in psychiatric hospitals, boarding places and hostels. The placement and staying of chronic patients under foster care providing the continuing therapeutic care can help prevent relapses, hospitalization, and cost of services as well as improve the quality of life, and the better functioning of the patients enabling them to lead to a more independent life in the future. [11-16-30-32]

\section{References}

[1] Spencer, R., Collins, M. E., Ward, R., \& Smashnaya, S. Mentoring for young people leaving foster care: Promise and potential pitfalls. Social Work.2010; 55(3): 225-234.

[2] Steadman HJ, Mulvey EP, Monahan J, Robbins PC, Appelbaum PS, Grisso T, Roth LH, Silver E. Violence by people discharged from acute psychiatric inpatient facilities and by others in the same neighborhoods. Arch. Gen. 
Psychiatry1998; 55: 393-401.

[3] Regional Health Board, Montreal (2004). Statistiques: re'partition des ressources d'he'bergement par e'tablissement gestionnaire pour Montreal et environs. Montreal, Quebec: Regie re'gionale de Montre'al-Centre.

[4] Madianos MG. Psychosocial rehabilitation (From Asylum to community). Greek Letters Publishing. Athens 1994.

[5] Damigos D.Social psychiatry in Greece, deinstitutionalization and her relation with primarily care. Papazisis publishing. Athens 2003.

[6] Papageorgiou - Vasilopoulou. Social and community mental health nursing. Beta publishing, Athens 2000.

[7] Madianos MG. Community psychiatry and community mental hygiene. Kastaniotis. Athens 2000.

[8] Jackie L Goldstein, Ph.D.Marc, M. L. Godemont, M.A. The Legend and Lessons of Geel, Belgium: A 1500-Year-Old Legend,a 21st-Century. Model Community Mental Health Journal. 2003; 39( 5):441-458.

[9] Roosens, E. Mental patients in town life: Geel-Europe's first therapeutic community. Sage Publications. London 1979

[10] Srole, L. The Geel family care research project: Introduction. Paper presented at The International Symposium on Foster Family Care, Geel, May, 1975 Belgium.

[11] Cowan, C., \& Cowan, P. Interventions to ease the transition to parenthood: Why they are needed and what they can do. Family Relations.1995; 44(4):412-423.

[12] Holtan, A., Ronning, J., Handegard, B., \& Sourander, A. (2005). A comparison of mental health problems in kinship and non kinship foster care. European Child and Adolescent Psychiatry.2005;14: 200-207.

[13] Shain, R. F. \& Phillips, J. The stigma of mental illness: Labeling and stereotyping in the news. In L. Wilkins and P. Peterson (Eds.), Risky business: Communicating Issues of Science, Risk and Public Policy. Westport, CT: Greenwood Press 1991: 61-74.

[14] Stein, L. Work and social support: A comparison of consumers who have achieved stability in ACT and clubhouse programs. Community Mental Health Journal.1999; 35 (2):193-204.

[15] Linn, M., Klett, C. J., \& Caffey, E. Foster home characteristics and psychiatric patient outcome: The wisdom of Geel confirmed. Archives of General Psychiatry.1980; 37:129 132.

[16] Schrijvers, J. Steadman, H. J., Mulvey, E. P., Monahan, J., Robbins, P.C., Appelbaum, P. S., Grisso, T., Roth, Why a congress about foster family care in Geel? Paper presented at The International Scientific Congress.2000 Geel, Belgium.

[17] O'Driscoll, C., \& Leff, J. The TAPS Project: Design of the research study on the long-stay patients. British Journal of Psychiatry.1993;162 (Suppl. 19): 18 - 24.

[18] Scannapieco M, Painter KR. Barriers to Implementing a Mentoring Program for Youth in Foster Care: Implications for Practice and Policy Innovation. Springer .New York 2013

[19] Corbie`re, M., Lesage, A., Reinharz, D., \& Contandriopoulos,
A-P. A French abridged version of the Hospitals and Hostels Practices Profile Schedule. International Journal of Methods in Psychiatric Research.2001;10:183 - 190.

[20] DuBois, D. L., Doolittle, F., Yates, B. T., Silverthorn, N., \& Tebes, J. K. Research methodology and youth mentoring. Journal of Community Psychology.2006;34(6):657-676.

[21] Grossman, J. B., \& Rhodes, J. E. The test of time: Predictors and effects of duration in youth mentoring relationships. American Journal of Community Psychology.2000; 30(2):199-219.

[22] Rhodes, J. E., Haight, W. L., \& Briggs, E. C. The influence of mentoring on the peer relationships of foster youth in relative and nonrelative care. Journal of Research on Adolescence.2000; 9(2): 185-201.

[23] Swartz, M. S., Swanson, J. W., Hiday, V. A., Borum, R., Wagner, H. R., \& Burns, B. J.Violence and severe mental illness: The effects of substance abuse and non adherence to medication. Am. J. Psychiatry. 1998;155:226-231.

[24] Piat M, Ricard N, Sabetti J, Beauvais L. The values and qualities of being a good helper: a qualitative study of adult foster home caregivers for persons with serious mental illness. Int J Nurs Stud. 2007;44(8):1418-29.

[25] Laan N M A, Loots G M P,Janssen C G C, Stolk J.«Foster care for children with mental retardation and challenging behaviour: A follow-up study. 2001;47(92):3-13

[26] Reid JB, Eddy JM, Fetrow RA, Stoolmiller M. Description and immediate impacts of a preventive intervention for conduct problems. American Journal of Community Psychology.1999; 27: 483-517.

[27] Piat M, Ricard N, Lesage A. Evaluating life in foster homes for persons with serious mental illness: Resident and caregiver perspectives. 2006;15(2): 227-242

[28] Tomaras V, Papageorgiou M, Soldatou M, Gournelis P. Towards to reintegration of the chronic mentally ill: Apilot foster home program. Psychiatry.2006;16(3):217-225.

[29] Glisson C, Green P. The role of specialty mental health care in predicting child welfare and juvenile justice out-of-home placements. Research on Social Work Practice.2006;16:480 490.

[30] Charmaz K. Constructing grounded theory: A practical guide through qualitative analysis. Sage. Thousand Oaks 2006.

[31] DuBois DL, Holloway B E, Valentine JC, Cooper H. Effectiveness of mentoring programs for youth: A metaanalytic review. American Journal of Community Psychology.2000;30(2): 157-197.

[32] BAZALIA F. Alternative Psychiatry.Ed \& Transalation Astrinakis G. Kastianiotis Publishing, Athens 2008.

[33] Shanahan MJ. Pathways to adulthood in changing societies: Variability and mechanisms in life course perspective. Annual Review of Sociology.2000; 26:667-692.

[34] Sobel M E. Asymptotic confidence intervals for indirect effects in structural equation models. In S. Leinhart (Ed.) Sociological methodology (pp. 290-312). Jossey-Bass. San Francisco 1982 
[35] Pierloot RA, Demarsin M. Significance of Geel foster family care to patients in a psychiatric hospital. Paper presented at
The International Symposium on Foster Family Care, 1975. Geel, Belgium. 